\title{
Structural Remodeling of Fibrous Astrocytes after Axonal Injury
}

\author{
Daniel Sun, Ming Lye-Barthel, Richard H. Masland, and Tatjana C. Jakobs \\ Massachusetts Eye and Ear Infirmary, Harvard Medical School, Boston, Massachusetts 02114
}

\begin{abstract}
Reactive astrocytes are a pathological hallmark of many CNS injuries and neurodegenerations. They are characterized by hypertrophy of the soma and processes and an increase in the expression of glial fibrillary acidic protein. Because the cells obscure each other in immunostaining, little is known about the behavior of a single reactive astrocyte, nor how single astrocytes combine to form the glial scar. We have investigated the reaction of fibrous astrocytes to axonal degeneration using a transgenic mouse strain expressing enhanced green fluorescent protein in small subsets of astrocytes. Fibrous astrocytes in the optic nerve and corpus callosum initially react to injury by hypertrophy of the soma and processes. They retract their primary processes, simplifying their shape and dramatically reducing their spatial coverage. At $3 \mathrm{~d}$ after crush, quantitative analysis revealed nearly a twofold increase in the thickness of the primary processes, a halving of the number of primary processes leaving the soma and an eightfold reduction in the spatial coverage. In the subsequent week, they partially reextend long processes, returning to a near-normal morphology and an extensive spatial overlap. The resulting glial scar consists of an irregular array of astrocyte processes, contrasting with their original orderly arrangement. These changes are in distinct contrast to those reported for reactive protoplasmic astrocytes of the gray matter, in which the number of processes and branchings increase, but the cells continue to maintain nonoverlapping individual territories throughout their response to injury.
\end{abstract}

\section{Introduction}

Astrocytes respond to many forms of CNS insults by becoming "reactive." They upregulate the expression of intermediate filaments [e.g., glial fibrillary acidic protein (GFAP), vimentin], the cell body, and processes hypertrophy, and the cells form a glial scar (Eddleston and Mucke, 1993; Ridet et al., 1997; Sofroniew, 2009; Sofroniew and Vinters, 2010). The immunocytochemical detection of GFAP has been a standard marker for reactive astrocytes. However, GFAP delineates only $\sim 15 \%$ of the total volume of an astrocyte (Connor and Berkowitz, 1985; Bushong et al., 2002), leaving the true morphology of an astrocyte unseen and making it difficult to differentiate between the many morphological types of astrocytes (Kettenmann and Ransom, 2005). Cytoplasmic markers can reveal the finer processes, but produce a labeling pattern with little visible separation between neighboring astrocytes. Therefore, although reactive gliosis is a stereotypic response of astrocytes to stress, for most types of astrocytes, it is unknown how an individual reactive astrocyte actually appears, and how a population of these cells remodels to form a glial scar.

The best-studied astrocytes, in terms of morphology and organization, are the protoplasmic astrocytes of the gray matter. By microinjection and using transgenic animals, these astrocytes have been visualized in detail. They are organized in nonoverlapping spatial domains, with overlap of only the most peripheral

Received July 12, 2010; accepted Aug. 14, 2010.

This work was supported by National Institutes of Health Grants R01 017169 (R.H.M.) and R01 EY019703 (T.C.J.) and by grants from The Glaucoma Foundation and the American Health Assistance Foundation (T.C.J.).

Correspondence should be addressed to Daniel Sun, Department of Ophthalmology, Massachusetts Eye and Ear Infirmary, 243 Charles Street, Boston, MA 02114. E-mail: daniel_sun@meei.harvard.edu.

DOI:10.1523/JNEUROSCI.3605-10.2010

Copyright $\odot 2010$ the authors $\quad 0270-6474 / 10 / 3014008-12 \$ 15.00 / 0$ processes of neighboring astrocytes (Bushong et al., 2002; Ogata and Kosaka, 2002; Halassa et al., 2007; Oberheim et al., 2008, 2009). After injury, reactive protoplasmic astrocytes in the hippocampus and cortex maintain their nonoverlapping spatial domains and thus the volume of neuropil they occupy, but the main processes hypertrophy and the number of primary processes leaving the soma increases. Overall, this increases the density of processes filling that volume (Wilhelmsson et al., 2006).

Fibrous astrocytes of the white matter are not organized into spatial domains, and the processes of neighboring astrocytes interdigitate extensively (Oberheim et al., 2009). Beyond the observation that GFAP expression is conspicuously upregulated, little is known of how fibrous astrocytes react to injury. Butt and Colquhoun (1996) used single-cell injections to demonstrate a simplification of the processes of individual astrocytes after a transection of the optic nerve proper of immature rats. Here, we have used a transgenic mouse strain that expresses enhanced green fluorescent protein (EGFP) in subsets of astrocytes to obtain a detailed visualization of many astrocytes (Nolte et al., 2001; Emsley and Macklis, 2006). We have studied the complete morphology and spatial arrangement of reactive fibrous astrocytes within three CNS structures: the glial lamina at the head of the optic nerve, the myelinated portion of the optic nerve, and the corpus callosum. We gave particular emphasis to the glial lamina, because in glaucoma this region is thought to be the primary site of insult leading to axonal degeneration and there are extensive changes in the GFAP labeling pattern here (Quigley, 1999; Howell et al., 2007; Buckingham et al., 2008; Soto et al., 2008). We found that fibrous astrocytes undergo a complex, two-stage process of remodeling that is distinctly different from the process in reactive protoplasmic astrocytes. 


\section{Materials and Methods}

Animals. All animal procedures were approved by the Research Animal Care Committee of the Massachusetts Eye and Ear Infirmary in Boston. Mice were housed in a $12 \mathrm{~h}$ light/dark cycle and received food and water ad libitum. Two mice strains were used in this study: (1) wild-type C57BL/6 (Charles River) and (2) transgenic mice in which astrocytes express EGFP under the control of the human GFAP promoter (hGFAPpr-EGFP). This strain was developed by injecting a $2.2 \mathrm{~kb}$ fragment of the human GFAP promoter fused to the EGFP gene into oocytes of FVB/N mice (Nolte et al., 2001). This strain shows bright labeling of sporadic individual astrocytes within the central (brain, retina, optic nerve) and peripheral nervous system. The green fluorescent cells in this mouse line do not include any neurons, oligodendrocytes, or microglia (Nolte et al., 2001; Emsley and Macklis, 2006; Sun et al., 2009). Our laboratory maintains a strain crossing hGFAPpr-EGFP mice with the DBA/2J line (The Jackson Laboratory), and for practical reasons, we used the offspring in some of our experiments. DBA/2J mice harbor two mutations (in the Gpnmb and Tyrp1 genes) that eventually lead these mice to develop glaucoma, first apparent at 6 months of age (Anderson et al., 2002; Libby et al., 2005). In these offspring, the expression pattern of EGFP was identical to that of the hGFAPpr-EGFP founder strain (Sun et al., 2009), and the animals used in our experiments were only 1-1.5 months old, well before the onset of any rise in intraocular pressure or glaucomatous changes. Furthermore, all the observations were confirmed with experiments in C57BL/6 and the hGFAPpr-EGFP founder strain. Heterozygous mice were used for all experiments involving transgenic animals, and EGFP expression was confirmed by inspecting the ears of adult animals under a dissecting microscope equipped for fluorescence microscopy.

Optic nerve crush and corpus callosum lesions. Mice were anesthetized with an intraperitoneal injection of $100 \mathrm{mg} / \mathrm{ml}$ ketamine and $20 \mathrm{mg} / \mathrm{ml}$ xylazine. For optic nerve crush, the nerve of one eye was exposed and clamped at either one of two locations: (1) immediately behind the globe at the posterior margin of the glial lamina or (2) $\sim 0.5 \mathrm{~mm}$ from the globe within the myelinated portion of the nerve. The clamp was performed for $10 \mathrm{~s}$ using a self-closing jeweler's forcep (FST self-closing forceps, curved tip). For corpus callosum lesions, a hole was drilled through the skull at the location of the bregma, and a 25 ga needle lowered $2 \mathrm{~mm}$ using a micromanipulator. The mice were killed at $3,7,14$, and $30 \mathrm{~d}$ after the surgery, and the brains or eyes were harvested. To ensure that the optic nerve crush did not affect the patency of the inner and outer retinal blood supply, we examined the pattern of the blood vessels after crush, labeled via a tail vein injection of 3\% Evan's blue immediately before the mice were killed. We did not observe any changes even after $7 \mathrm{~d}$ after crush (Fig. 1).

5-Bromo-2'-deoxyuridine administration. Studies of cell proliferation on animals that underwent optic nerve crush were performed with the thymidine analog 5-bromo-2'-deoxyuridine (BrdU; Sigma) dissolved in sterile saline. Animals were initially given an intraperitoneal injection of $\mathrm{BrdU}(100 \mathrm{mg} / \mathrm{kg}) 1 \mathrm{~h}$ after the nerve crush and then once per day for the next 3 or $7 \mathrm{~d}$ after the crush, until they were killed. Corresponding control animals were identically treated.

Terminal deoxynucleotidyl transferase-mediated dUTP nick end labeling. Terminal deoxynucleotidyl transferase-mediated dUTP nick end labeling (TUNEL) was performed with a Fluorescein In Situ Cell Detection kit (Roche Applied Science) according to the manufacturer's instructions. As positive controls, some sections were treated with DNase I ( $1 \mu \mathrm{g} / \mathrm{ml}$; Sigma) before the TUNEL reaction.

Tissue preparation. The skull was opened to expose the brain. Forceps were then used to carefully separate the brain from the optic nerve and chiasm. If needed, the brain was immediately immersed in $4 \%$ paraformaldehyde overnight at $4^{\circ} \mathrm{C}$. The head containing the optic nerve was fixed for $1 \mathrm{~h}$ at room temperature. After fixation, both tissues were washed in $0.1 \mathrm{~m}$ PBS ( $\mathrm{pH} 7.4$, three times for $10 \mathrm{~min}$ ). The procedure for removing the optic nerve from the skull has been described previously (Sun et al., 2009). Optic nerves were sucrose (30\%) protected overnight, mounted in freezing medium, cryosectioned at $14 \mu \mathrm{m}$ thickness, collected on coated slides, and stored in the freezer until use. The brain was
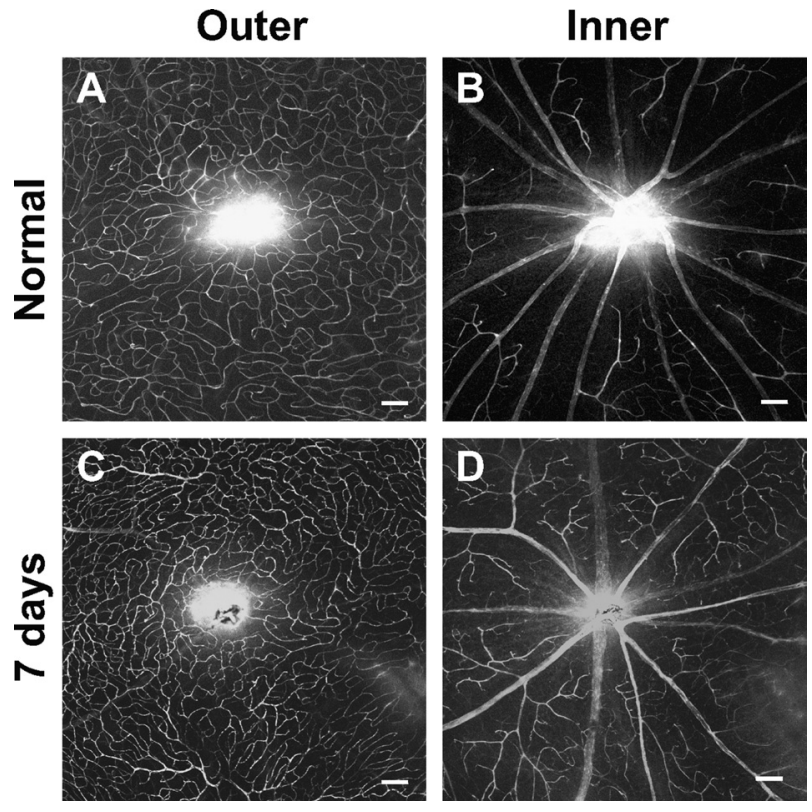

Figure 1. Optic nerve crush did not alter the pattern of the retinal blood vessels. A tail vein injection of 3\% Evan's blue was performed to trace the blood vessel pattern of the retina. Whole-mount retinal images show that the outer $(\boldsymbol{A}, \boldsymbol{C})$ and inner $(\boldsymbol{B}, \boldsymbol{D})$ retinal blood vessel pattern was similar in the normal $(\boldsymbol{A}, \boldsymbol{B})$ and $7 \mathrm{~d}$ after crush $(\boldsymbol{C}, \boldsymbol{D})$ animals. Scale bars, $100 \mu \mathrm{m}$.

embedded in $4 \%$ agarose and sectioned at $150 \mu \mathrm{m}$ in the coronal plane using a vibratome.

Immunofluorescence. Optic nerve and brain sections were incubated in blocking solution (3\% donkey serum, $0.5 \%$ Triton X-100, $0.01 \% \mathrm{NaN}_{3}$ in PBS) for $1 \mathrm{~h}$ at room temperature. Sections were then incubated in primary antibodies diluted in blocking solution overnight (optic nerve sections) or for 4-5 d (brain sections) at room temperature, after which they were washed in PBS ( $\mathrm{pH} 7.4$, three times for $10 \mathrm{~min}$ ). For BrdU staining, sections were treated for antigen retrieval using the $\mathrm{HCl}$ denaturation process. Sections were transferred to $2 \mathrm{~N} \mathrm{HCl}$ for $30 \mathrm{~min}$ at $37^{\circ} \mathrm{C}$, rinsed in PBS (three times for $10 \mathrm{~min}$ ), and blocked before the primary antibody was applied. The primary antibodies used were as follows: rabbit anti-GFAP (1:2000; Abcam), mouse anti-SMI32 (1:200; Covance), rabbit anti-NG2 (1:200; Millipore), rat anti-CD11b (1:200; Abcam), mouse anti-vimentin (1:100; Abcam), rabbit anti-S100 $\beta$ (1:200; Abcam), rabbit anti-myelin basic protein (MBP; 1:400; Abcam), and rabbit antiPCNA (1:250; Abcam). Sections were then washed in PBS (three times for $10 \mathrm{~min}$ ) and incubated in secondary antibodies conjugated with fluorescein isothiocyanate (1:400, donkey anti-rabbit; Jackson ImmunoResearch) or rhodamine (1:400, donkey anti-rabbit, -rat, and -mouse; Jackson ImmunoResearch). Secondary antibodies were applied for at least overnight at room temperature and subsequently washed in PBS (three times for $10 \mathrm{~min}$ ).

Particle-mediated dye transfer. The Helios Gene Gun System (16502431; Bio-Rad) was used to deliver tungsten particles coated with lipophilic dyes into agarose-embedded sections of the optic nerve. Preparations of the DiI bullets have been described previously (Gan et al., 2000; Kong et al., 2005). Briefly, 300-400 $\mu$ l of methylene chloride was added to $20 \mathrm{mg}$ of tungsten beads $(1.1 \mu \mathrm{m})$ and $3 \mathrm{mg}$ of DiI (Invitrogen). The mixture was sonicated, poured onto a glass slide to air dry, scraped off, and placed in $3 \mathrm{ml}$ of distilled water. The solution was drawn into Tefzel tubing using a syringe and rotated using the tubing prep station (165-2431; Bio-Rad) for $5 \mathrm{~min}$. The water was slowly drawn out of the tube using a syringe, and the tube was allowed to air dry for $5 \mathrm{~min}$ before cutting into bullets using the tube cutter. The coated tubing was loaded into the Helios Gene Gun (Bio-Rad), and the optic nerves were shot at $120-160$ psi.

Image collection and analysis. Images were acquired on a Radiance laser-scanning confocal microscope (Bio-Rad) equipped with $\mathrm{Kr} / \mathrm{Ar}$ and 

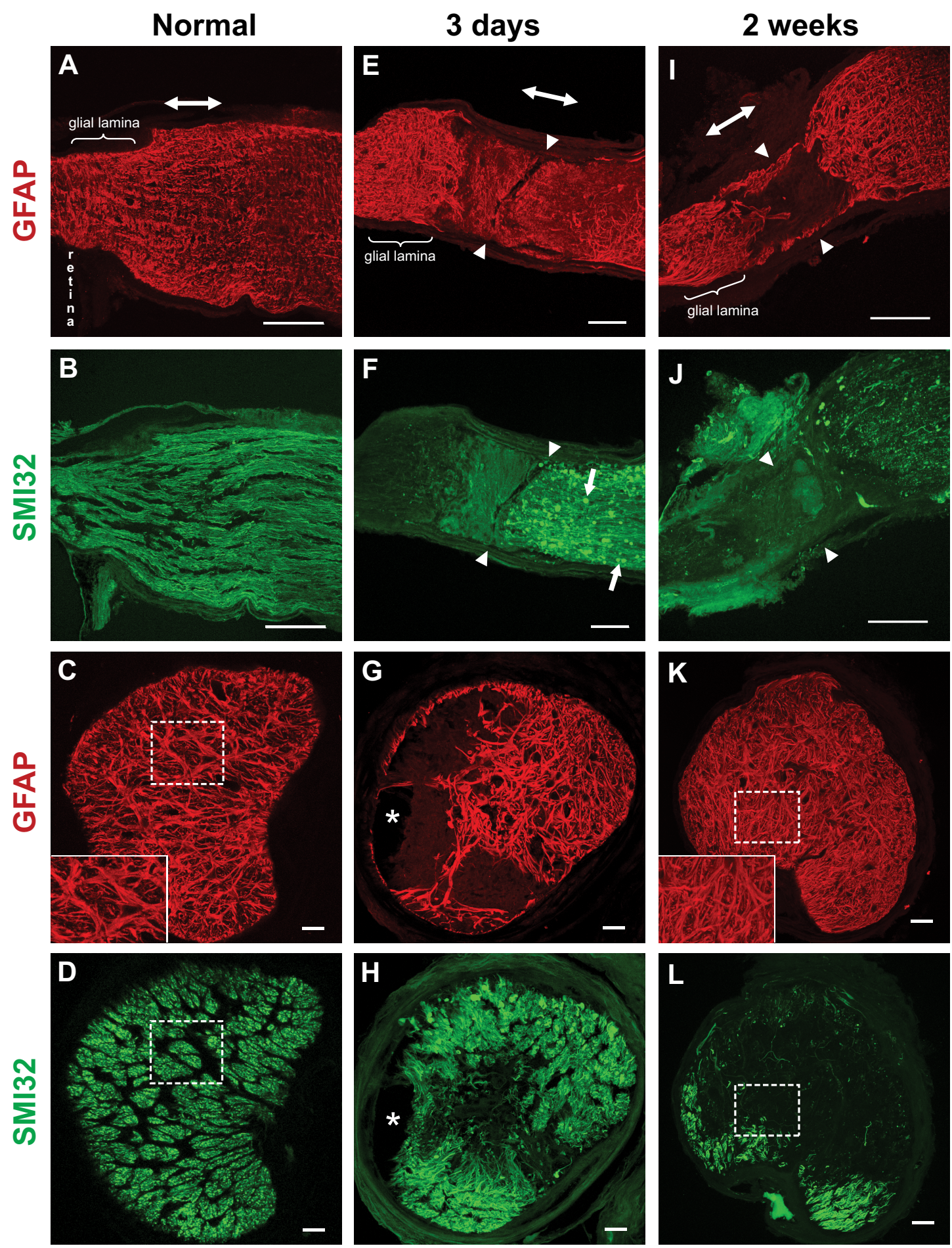

M

$\mathbf{N}$
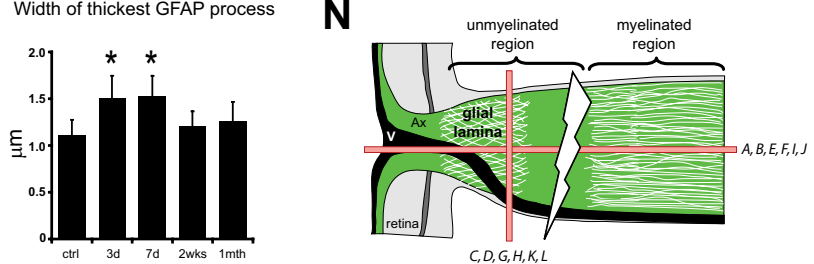

Figure 2. Longitudinal $(\boldsymbol{A}, \boldsymbol{B}, \boldsymbol{E}, \boldsymbol{F}, \boldsymbol{I}, \boldsymbol{J})$ and transverse $(\boldsymbol{C}, \boldsymbol{D}, \mathbf{G}, \boldsymbol{H}, \boldsymbol{K}, \boldsymbol{L})$ sections of the optic nerve labeled for GFAP (astrocyte processes) and SMI32 (axons) in the normal and crushed optic nerve. $A-D$, Within the normal glial lamina, the processes of astrocytes were transversely arranged $(A, B)$ and segregate neighboring axons into bundles, forming glial tubes $(C, D$, dashed square) and giving this region a honeycomb appearance $(\boldsymbol{C}, \boldsymbol{D})$. The inset in $\boldsymbol{C}$ is an enlargement of the dashed square. $\boldsymbol{E}, \boldsymbol{F}, \mathrm{At} 3 \mathrm{~d}$ after crush, there was a loss of processes at the crush site (arrowheads) and of axons proximal to the crush site; disorganization and hypertrophy of the processes, especially in the central region of the glial lamina; and axonal swellings ( $\boldsymbol{F}$, arrows). $\mathbf{G}, \boldsymbol{H}$, (Figure legend continues.) 

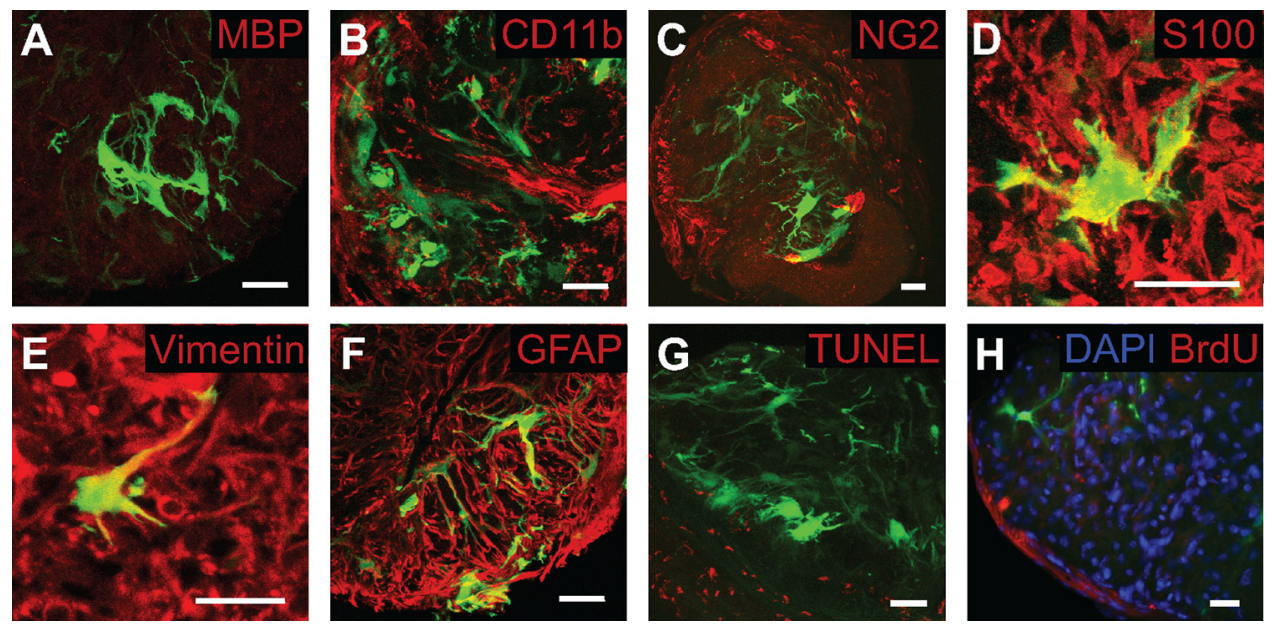

Figure 3. EGFP-expressing cells in the glial lamina of the $7 \mathrm{~d}$ after crushed optic nerve were not oligodendrocytes, microglia, or NG2 cells. A-C, There was no colocalization of EGFP-expressing cells with immunocytochemical markers for oligodendrocytes (MBP; $\boldsymbol{A})$, microglia (CD11b; $\boldsymbol{B})$ or NG2 cells (NG2; $\boldsymbol{C}$. D-F, However, EGFP-expressing cells colocalized with S100 $\beta(\boldsymbol{D})$, vimentin $(\boldsymbol{E})$, and GFAP $(\boldsymbol{F})$, three common markers of astrocytes (colocalization is $<100 \%$ because the molecules are not present in the nucleus). $\mathbf{G}, \boldsymbol{H}$, The morphological changes observed in EGFP-expressing cells after the crush injury were not caused by apoptotic cell death (assessed by TUNEL staining; $\boldsymbol{G}$ ) or cell proliferation (assessed by BrdU staining; $\boldsymbol{H}$ ). Scale bars, $20 \mu \mathrm{m}$.

$\mathrm{CO}_{2}$ lasers mounted on a Zeiss Axioscope II. Water-immersion lenses $25 \times / 0.8$ Plan-Apochromat, $40 \times / 1.2$ C-Apochromat, and $63 \times / 1.2$ C-Apochromat (Carl Zeiss) were used. Images were taken using the Lasersharp 2000 software (Bio-Rad) and exported into ImageJ (National Institutes of Health) software. Images are either single focal plane scans or a maximum-intensity projection of a stack of images made at a step size of $0.3-0.5 \mu \mathrm{m}$. The brightness and contrast of the final images were adjusted using Adobe Photoshop CS2; no other digital image processing was performed. Each panel in the figures represents a typical finding from a sample of four to six mice.

The width of the thickest astrocyte process was measured at a location $12-15 \mu \mathrm{m}$ away from the nucleus. This was performed for both GFAPlabeled and EGFP-expressing processes. Quantification of the number of primary processes leaving the soma was determined from threedimensional reconstructed images of the EGFP-expressing astrocytes. The convex hull of an astrocyte was determined from maximumintensity projections and defined as the area enclosed by a convex polygon formed by touching the longest processes of the astrocyte. Astrocytes within the glial lamina are relatively flat (Sun et al., 2009), so that the area covered by a single cell could be measured on the projection of its processes in the transverse plane. The spatial coverage was the convex hull area as a percentage of the total cross-sectional surface area of the optic nerve. The means and SEMs were calculated, and the differences between experimental and control groups were tested using an ANOVA test with significance determined to occur when $p<0.05$.

\section{Results}

Reactive fibrous astrocytes in the glial lamina-GFAP labeling The normal optic nerve head of the mouse contains a specialized region called the glial lamina, where GFAP-labeled processes are particularly dense and are transversely oriented with respect to the long axis of the optic nerve (Fig. $2 A, B$ ). In transverse section,

\footnotetext{
(Figure legend continued.) There were also fluid-filled cyst formations (asterisks). J, L, At 2 weeks after crush, there was a greater loss of axons. $\boldsymbol{I}, \boldsymbol{K}$, The processes of astrocytes were not as thick as at $3 \mathrm{~d}$ after crush, and the areas devoid of axons are now filled with a dense and disorganized array of processes $(\boldsymbol{K})$. The inset in $\boldsymbol{K}$ is an enlargement of the dashed square. There were no longer any glial tube formations. $M$, Morphometric analysis of the thickness of the processes within the glial lamina based on GFAP labeling (mean \pm SEM; ${ }^{*} p<0.05$ ). $\boldsymbol{N}$, The schematic depicts the crush site (thunderbolt) and how the optic nerve was sectioned (red bars). The double-headed arrow in $A, E$, and $I$ indicates the direction of the long axis of the optic nerve. Ax, Axons; V, blood vessel. Scale bars, $100 \mu \mathrm{m}$.
}

these processes partition neighboring ganglion cell axons into bundles, forming glial tubes and giving the glial architecture of this region a honeycomb appearance (Fig. $2 C, D$ ). A typical glial tube arrangement is shown in the inset in Figure $2 C$, where numerous thick processes combine to form the walls of the glial tube, whereas short thin processes run into the center of the glial tube. The average thickness of the main processes was $1.10 \pm 0.17$ $\mu \mathrm{m}$ (Fig. $2 M)(n=46$ processes, 5 mice). The glial lamina contains no oligodendrocytes or NG2 glial cells. The architecture of the normal glial lamina has been described previously in depth (Howell et al., 2007; Sun et al., 2009).

Three days after crush, the optic nerve showed axonal loss and remodeling of the GFAP-labeled processes (Fig. $2 \mathrm{E}-H$ ). The processes within the glial lamina were disorganized, hypertrophied, and no longer arranged to form glial tubes (Fig. $2 E-H$ ). In this example, the processes were particularly thick within the central region of the glial lamina (Fig. $2 G$ ). Interestingly, astrocyte processes were present in areas devoid of axons and vice versa (Fig. $2 G, H)$. The axons distal to the crush site died through Wallerian degeneration and showed bulbous swellings (Fig. $2 F$, arrows). The glial lamina also showed numerous fluid-filled cysts (Fig. $2 G, H$, asterisks). Morphometric analysis indicates that the GFAP-labeled processes were thickest at 3 and $7 \mathrm{~d}$ after crush (Fig. $2 M)(3 \mathrm{~d}: 1.51 \pm 0.24 \mu \mathrm{m} ; n=30$ processes, 5 mice; $7 \mathrm{~d}$ : $1.52 \pm 0.22 \mu \mathrm{m} ; n=38$ processes, 5 mice). There was no significant difference in the thickness of the processes between 3 and $7 \mathrm{~d}$ after crush.

At 2 weeks, the optic nerve showed a severe loss of axons and the formation of a glial scar (Fig. 2I-L). The glial lamina was completely filled with a dense, tightly packed meshwork of disorganized processes such that there were no areas devoid of GFAP labeling (Fig. 2, compare $K$, inset, $\mathrm{C}$, inset). The honeycomb appearance of this region was disrupted (originally formed by thick bundles of GFAP-labeled processes) (Sun et al., 2009), and there appeared to be a greater number of short thin processes. Without the presence of axons, the astrocyte processes no longer formed glial tubes (Fig. $2 K, L$ ). At this stage, the processes were no longer as thick as at $3 \mathrm{~d}$ after crush (Fig. $2 K, M)(1.20 \pm 0.14 \mu \mathrm{m} ; n=40$ processes, 5 mice). 

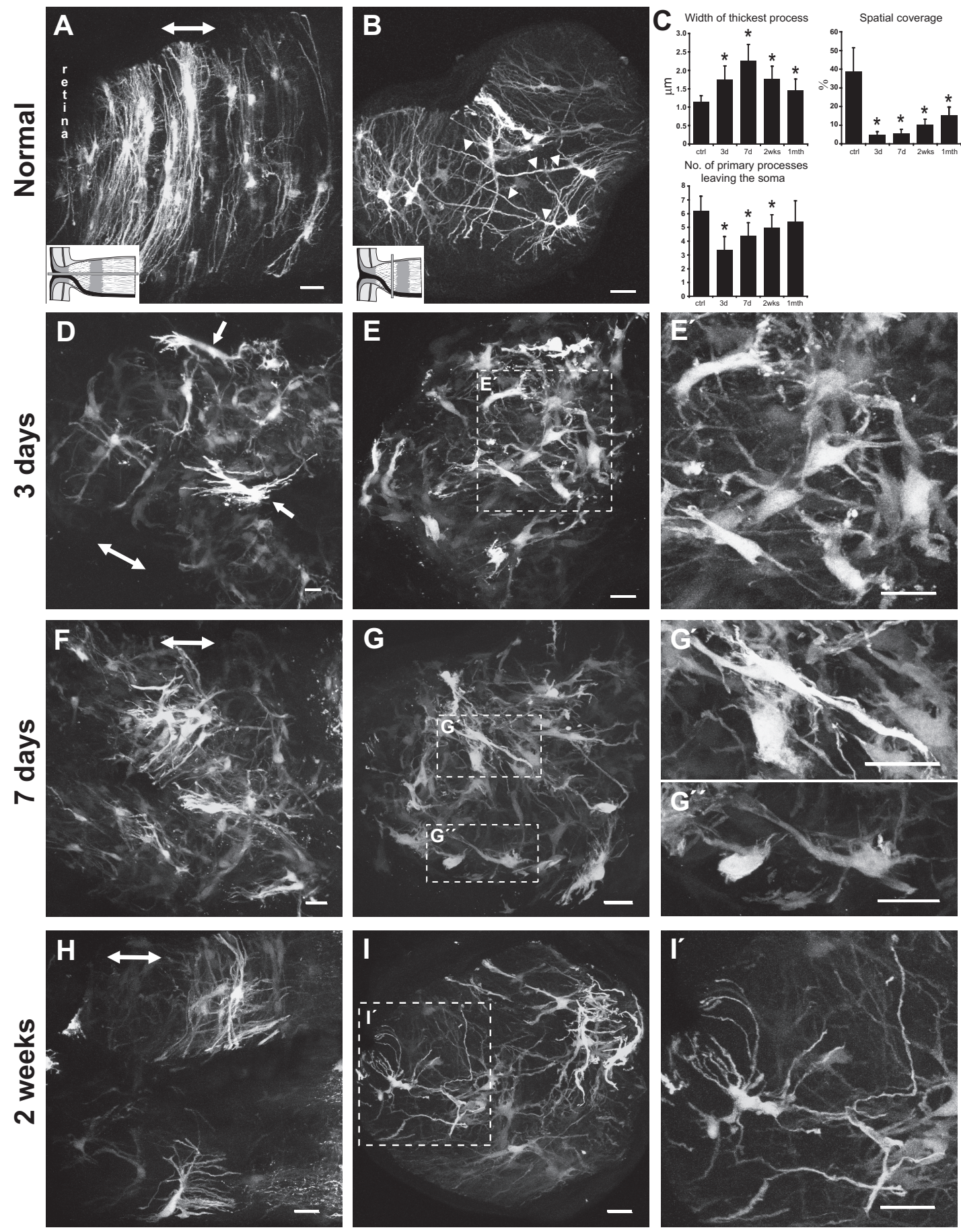

Figure 4. Normal and reactive fibrous astrocytes in the glial lamina of the hGFAPpr-EGFP mouse. $\boldsymbol{A}, \boldsymbol{B}, \boldsymbol{D}-\boldsymbol{I}$, Images are either longitudinal $(\boldsymbol{A}, \boldsymbol{D}, \boldsymbol{F}, \boldsymbol{H})$ or transverse $(\boldsymbol{B}, \boldsymbol{E}, \boldsymbol{G}, \boldsymbol{I})$ sections of the glial lamina and represent maximum intensity projections. $\boldsymbol{A}$, Normal astrocytes in the glial lamina have processes that are transversely arranged to form a sheet-like arrangement. $\boldsymbol{B}$, They have long primary processes that traverse the entire width of the optic nerve to contact the pial wall (arrowheads). The processes of neighboring astrocytes overlap extensively. At $3 \mathrm{~d}$ after crush, astrocytes become reactive and show hypertrophy of the soma and remaining processes. $\boldsymbol{D}, \boldsymbol{E}^{\prime}$, They retract their primary and higher-order processes and lose their transverse orientation (arrows). The shortening of processes reduces the spatial coverage of individual astrocytes. $\boldsymbol{F}-\boldsymbol{I}$, These changes persist to $7 \mathrm{~d}$ after crush $\left(\boldsymbol{F}-\boldsymbol{G}^{\prime \prime}\right)$, and by 2 weeks $\left(\boldsymbol{H}-\boldsymbol{I}^{\prime}\right)$, there is a thinning and reextension of the processes, although they never recover their original length. These processes follow a tortuous path and do not form glial tubes. $C$, Morphometric analysis shows that these morphological changes are most severe at $3-7 \mathrm{~d}$ after crush, showing a gradual recovery by 2 weeks and 1 month after crush (mean \pm SEM; ${ }^{*} p<0.05$ ). The schematic in $A$ and $B$ depicts how the optic nerve was sectioned (gray bars) and applies to their respective columns. The double-headed arrow in $\boldsymbol{A}, \boldsymbol{D}, \boldsymbol{F}$, and $\boldsymbol{H}$ indicates the direction of the long axis of the optic nerve. Scale bars, $20 \mu \mathrm{m}$.

Reactive fibrous astrocytes in the glial lamina remodeling of individual astrocytes

GFAP labeling does not reveal the complete morphology of individual astrocytes. We therefore used transgenic mice (hGFAPpr-EGFP) that express EGFP in subsets of astrocytes to reveal their complete morphology in the normal and crushed optic nerve (see Fig. $4 A-I^{\prime}$ ). Seven days after crush, colocalization of the EGFP-expressing cells with antibodies against MBP, CD11b, and NG2 demonstrated they were not oligodendrocytes, microglia, or NG2 cells, but astrocytes, as they colocalized with vimentin, $S 100 \beta$, and GFAP (Fig. $3 A-F$ ) (data not shown for other time points). As determined by 

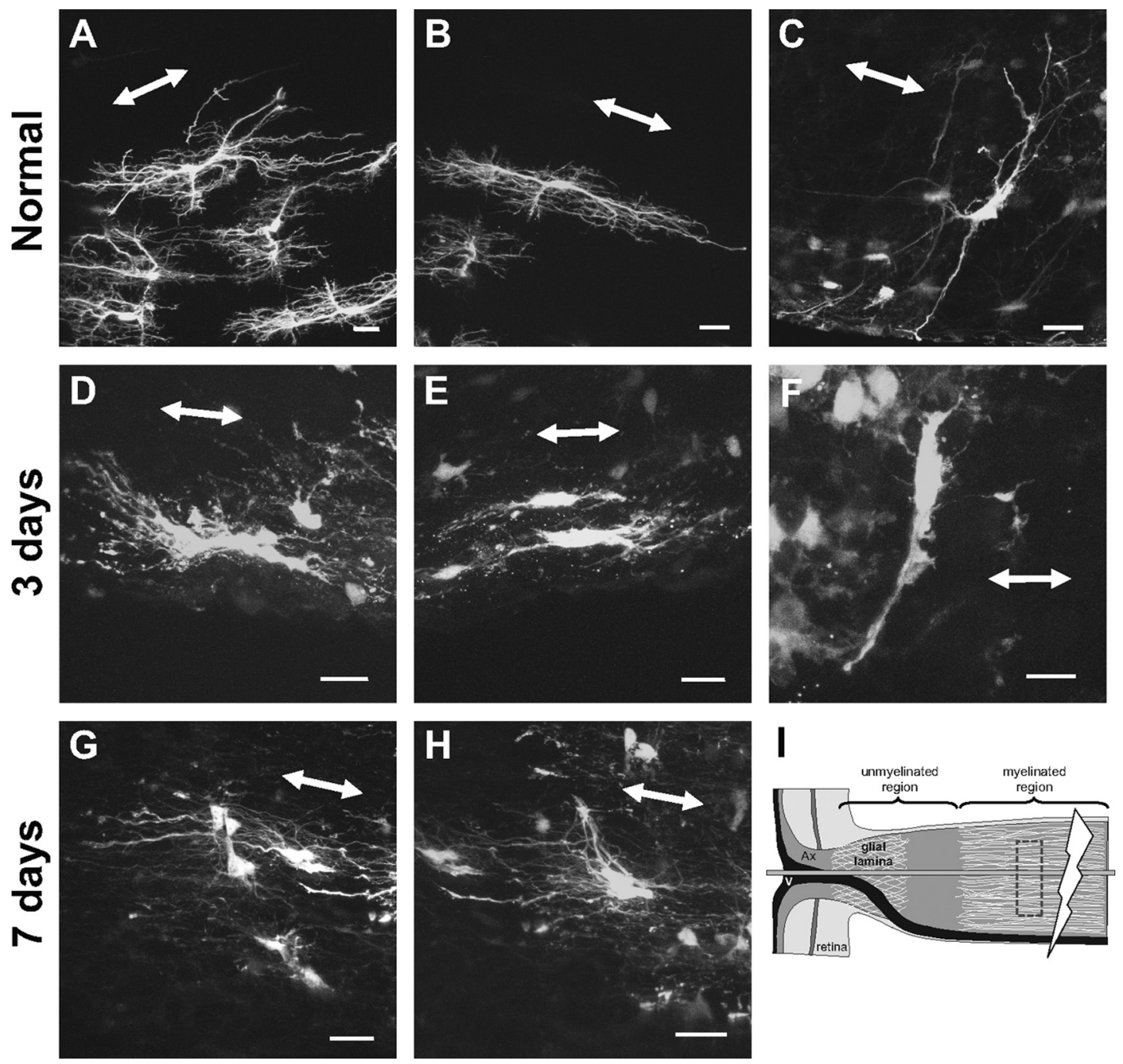

Figure 5. Reactive fibrous astrocytes in the myelinated optic nerve of the hGFAPpr-EGFP mouse showed similar morphological changes to those observed in the glial lamina. $\boldsymbol{A}-\boldsymbol{H}$, Individual fibrous astrocytes from the normal $(\boldsymbol{A}-\boldsymbol{C})$ and crushed $(\boldsymbol{D}-\boldsymbol{H})$ myelinated optic nerve. Longitudinally oriented astrocytes were hairy in appearance, with many small fine processes projecting from the primary processes $(\boldsymbol{A}, \boldsymbol{B})$. Transversely oriented astrocytes have long thin slender primary processes that reach out to contact the pial wall $(\boldsymbol{C})$. Three days after crush, these astrocytes showed changes similar to those for reactive astrocytes of the glial lamina: hypertrophy of the soma and remaining processes and retraction of their primary and higher-order processes $(\boldsymbol{D}-\boldsymbol{F})$. At $7 \mathrm{~d}$ after crush, many of the primary processes have reextended. The small fine processes that emanate from the primary processes do not return $(\boldsymbol{G}, \boldsymbol{H}) . \boldsymbol{I}$, The schematic depicts the crush site (thunderbolt), the location of the imaged astrocytes (dashed box), and how the optic nerve was sectioned (horizontal gray bar). The double-headed arrow in each panel indicates the direction of the long axis of the optic nerve. Ax, Axons; V, blood vessel. Scale bars, $20 \mu \mathrm{m}$.

TUNEL labeling, the morphological changes after the crush injury were not attributable to apoptosis (Fig. $3 G$ ). Labeling with BrdU demonstrated there was no significant cell proliferation (Fig. $3 H$ ) (also confirmed by staining with PCNA; data not shown).

In the normal glial lamina, individual astrocytes have thick, elongated cell bodies and processes preferentially oriented transversely to the long axis of the optic nerve (Fig. 4A). These astrocytes rarely project extensive longitudinal processes, and, collectively, they form sheets aligned transversely across the optic nerve (Fig. $4 A$ ). In a transverse section, the primary processes appear as dense trunks emanating from a cytoplasmic extension of the soma (Fig. $4 B$, arrowhead). These processes often span the entire width of the optic nerve to contact the pial wall or blood vessels. In addition, many short fine processes project directly from the soma. The morphology of these astrocytes has been described previously in depth (Sun et al., 2009). Quantitatively, the width of the thickest process was $1.14 \pm 0.17 \mu \mathrm{m}$, consistent with measurements based on the GFAP labeling (Fig. $2 M$ ). The number of primary processes leaving the soma was $6.19 \pm 1.08$. Astrocytes within the glial lamina are relatively flat cells (Sun et al., 2009), so that the area covered by a single cell could be measured from the projection of its processes in the transverse plane. The convex hull, here defined as the area enclosed by a convex polygon touching the longest processes, was $15,023 \pm 2,563 \mu \mathrm{m}^{2}$ (45 cells, 5 mice). The spatial coverage (convex hull as a percentage of the total cross-sectional surface area of the optic nerve) was $38.57 \pm 12.9 \%$.

At $3 \mathrm{~d}$ after crush, EGFP expression revealed striking morphological changes in reactive fibrous astrocytes of the glial lamina. There was hypertrophy of the processes and cell bodies, retraction of primary processes (a reduction in the number of processes and branching), and a loss of their transverse orientation (Fig. $4 D-E^{\prime}$, arrows). Many small fine processes, especially those that emanate directly from the soma, were also lost. Quantitatively, the processes of these reactive astrocytes thickened by 

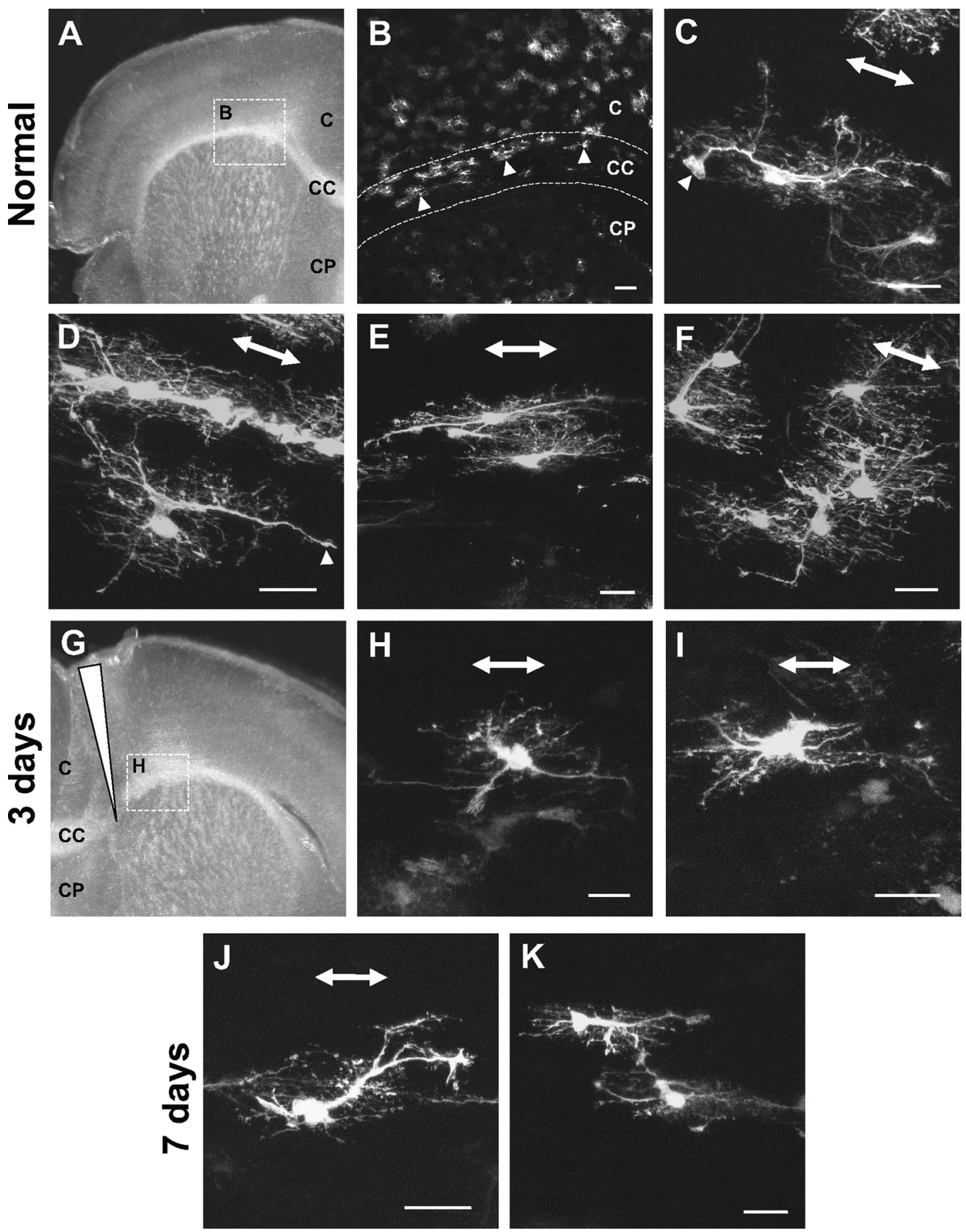

Figure 6. Reactive fibrous astrocytes in the corpus callosum showed morphological changes similar to those observed in the glial lamina and myelinated optic nerve. $\boldsymbol{A}, \boldsymbol{B}, \mathrm{A}$ survey image from a section of the corpus callosum showed many EGFP-expressing astrocytes within this region of the hGFAPpr-EGFP mouse (arrowheads). Astrocytes in the normal corpus callosum were similar in appearance to astrocytes in the myelinated optic nerve. $(-\boldsymbol{F}$, Their main processes run parallel to the nerve fibers, they have many short fine processes, and the processes of neighboring astrocytes overlap extensively. They have a process that ends with a large endfoot contacting a blood vessel ( $\boldsymbol{C}, \boldsymbol{F}$, arrowheads). $\mathbf{G}-\boldsymbol{I}$, Three days after a cortical stab lesion (long arrowhead), reactive astrocytes retract many of their primary and higher-order processes $(\boldsymbol{H}, \boldsymbol{I}) . \boldsymbol{J}, \boldsymbol{K}$, Some of the primary processes have partially reextended by $7 \mathrm{~d}$ after crush. C, Cortex; $C \mathrm{C}$, corpus callosum; $(\mathrm{CP}$, caudate-putamen. Scale bars: $\boldsymbol{B}, 100 \mu \mathrm{m} ; \boldsymbol{A}, \boldsymbol{C}-\boldsymbol{K}, 20 \mu \mathrm{m}$.

nearly twofold and the number of primary processes leaving the soma halved (Fig. 4C) (width of the thickest process was $1.74 \pm$ $0.38 \mu \mathrm{m}$; number of primary processes leaving the soma was $3.38 \pm 0.96$; convex hull was $1398 \pm 437 \mu \mathrm{m}^{2}$ ). The spatial coverage of an individual reactive astrocyte diminished almost eightfold to $\sim 5 \%$ of the total surface area of the glial lamina (Fig. 4C) (spatial coverage was $4.63 \pm 1.9 \% ; n=50$ cells, 6 mice). The glial tubes through which axon bundles once passed are gone. Instead, the glial lamina is filled with a disorganized array of hypertrophied astrocytes (Fig. $4 E, E^{\prime}$ ).

The morphological changes persisted to $7 \mathrm{~d}$ after crush (Fig. $4 F-G^{\prime \prime}$ ). At this time, the thickness of the astrocyte processes was maximal, and many astrocytes reextended some processes (Fig. $4 G^{\prime}, G^{\prime \prime}$ ). There was a small but significant in- 


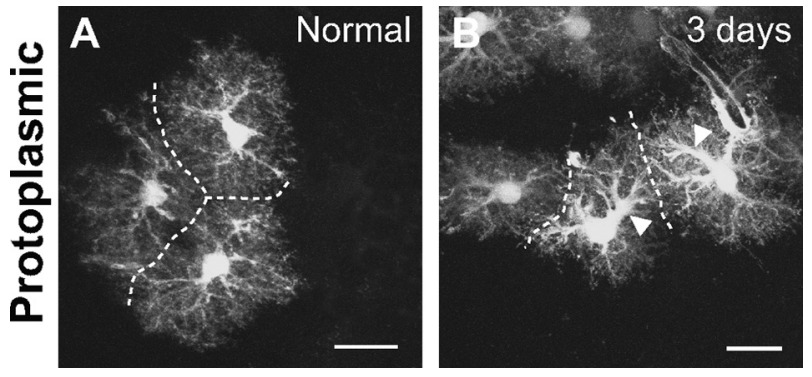

Figure 7. Normal and reactive protoplasmic astrocytes in the cortex. A, Protoplasmic astrocytes have a bushy morphology with many fine processes. They maintain nonoverlapping spatial domains: the dashed line demarcates the boundary of neighboring astrocytes. $\boldsymbol{B}$, Three days after a stab lesion, reactive protoplasmic astrocytes undergo hypertrophy of their primary processes (arrowheads) but maintain nonoverlapping spatial domains. Scale bars, $20 \mu \mathrm{m}$.
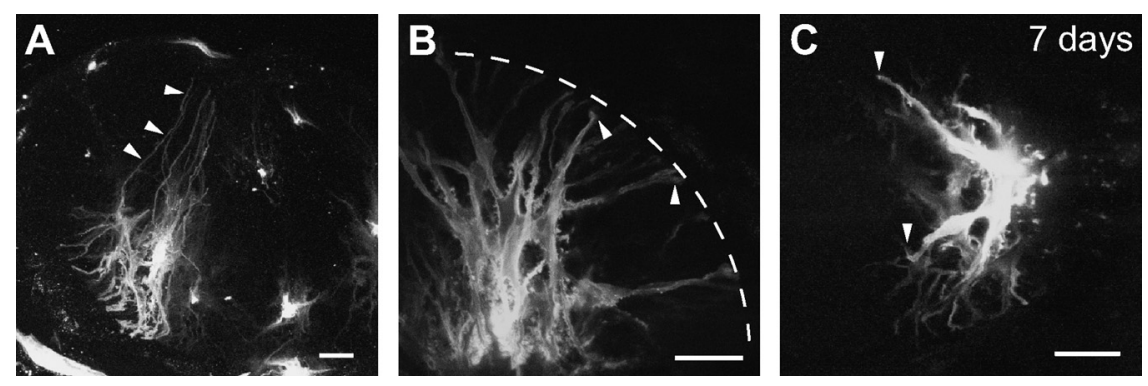

Figure 8. Particle-mediated dye labeling of normal $(\boldsymbol{A}, \boldsymbol{B})$ and reactive $(\boldsymbol{C})$ astrocytes within the glial lamina of the $(57 \mathrm{BL} / 6$ mouse. As an alternative method of confirming the reactive changes observed in the hGFAPpr-EGFP mouse, we diolistically labeled astrocytes within the normal and crushed glial lamina. $\boldsymbol{A}, \boldsymbol{B}$, Astrocytes labeled this way had a similar morphology to those observed in the hGFAPpr-EGFP mouse; in the transverse section, they have long thin slender processes that often traversed the entire width of the optic nerve ( $\boldsymbol{A}$, arrowheads) and contacted the pial wall with bulbous endfeet ( $\boldsymbol{B}$, arrowheads). $\boldsymbol{C}$, Seven days after crush, there was retraction of the primary processes and hypertrophy of the remaining processes (arrowheads). There is less contrast by this method of labeling because Dil distributes mainly within the plasma membrane, whereas EGFP fills the soma and processes. Scale bars, $20 \mu \mathrm{m}$.

crease in the number of primary processes leaving the soma, compared with $3 \mathrm{~d}$ after crush (Fig. 4C) (width of the thickest process was $2.26 \pm 0.44 \mu \mathrm{m}$; number of primary processes leaving the soma was $4.38 \pm 0.96$; convex hull was $2337 \pm 985$ $\mu \mathrm{m}^{2}$; spatial coverage was $5.15 \pm 2.70 \% ; n=48$ cells, 5 mice). Moreover, the spatial organization of the reactive astrocytes was still severely disrupted (Fig. $4 G$ ).

By 2 weeks after crush, the morphological appearance of individual reactive astrocytes recovered. In longitudinal section, the general shape of these astrocytes appeared close to normal (Fig. $4 \mathrm{H}$ ). The length of the processes increased compared to $7 \mathrm{~d}$ after crush, the thickness of the primary processes was reduced, and the number of primary processes leaving the soma increased (Fig. $\left.4 C, I, I^{\prime}\right)$. However, there was no recovery of the small fine processes. The width of the thickest process was $1.77 \pm 0.34 \mu \mathrm{m}$, the number of primary processes leaving the soma was $4.89 \pm 1.27$, convex hull was $2923 \pm 764 \mu \mathrm{m}^{2}$, and spatial coverage was $10.12 \pm 3.11 \%$ ( $n=47$ cells, 6 mice $)$. The GFAP labeling pattern seen in Figure $2 \mathrm{~K}$ was made up of these shorter than normal and thin processes, many of which followed a tortuous path, disrupting the previously regular organization of the glial tubes. One month after crush, both the thickness and the number of processes leaving the soma had returned to near normal levels, although the length of their processes remained somewhat shorter than normal, reducing the spatial coverage (Fig. $4 C$ ). The width of the thickest process was $1.45 \pm 0.32 \mu \mathrm{m}$, the number of primary processes leaving the soma was $5.4 \pm 1.52$, convex hull was
$9473 \pm 1254 \mu \mathrm{m}^{2}$, and spatial coverage was $14.96 \pm 4.42 \%(n=$ 39 cells, 5 mice).

\section{Reactive fibrous astrocytes in the myelinated optic nerve and corpus callosum}

The glial lamina is a specialized region of the optic nerve head where the ganglion cell axons are unmyelinated. To determine whether the reactive phenotype of astrocytes in the glial lamina was representative of fibrous astrocytes more generally, we examined reactive astrocytes in the myelinated portion of the optic nerve and the corpus callosum (Fig. 5). Normal astrocytes within the myelinated optic nerve exhibit a wide spectrum of shapes, sizes, and orientation. The various forms of these astrocytes have been described in detail previously (Butt et al., 1994a,b; Sun et al., 2009). For simplicity, we describe here astrocytes at the extremes of the spectrum of orientation, which we will term longitudinally and transversely oriented astrocytes (Fig. 5A-C). Longitudinal astrocytes have primary processes that run in parallel to the long axis of the optic nerve. They are typically "hairy" in appearance, with many small offshoot branches (Fig. 5A,B). Transversely oriented astrocytes have thin, elongated cell bodies; primary processes that run perpendicular to the long axis of the optic nerve and extend to the pial wall; and have few higher-order branches (Fig. 5C). Three days after crush, both longitudinally and transversely oriented astrocytes retract their primary and higher-order processes, reducing the number of processes and branchings. This was similar to the remodeling of reactive astrocytes within the glial lamina. However, the remaining processes showed less hypertrophy (Fig. 5D-F). By $7 \mathrm{~d}$, the primary processes have partially reextended, but not the small offshoot branches (Fig. 5G,H).

Fibrous astrocytes in the normal corpus callosum have a similar appearance to those in the myelinated optic nerve, in that the processes run in parallel to the path of the nerve fibers; they have an overall hairy appearance, and the processes of neighboring astrocytes overlap extensively (Fig. $6 A-F$ ). In many cases, these astrocytes have a thick prominent primary process that ends with a large endfoot contacting a blood vessel (Fig. 6C,D, arrowheads). Three days after a cortical stab lesion, the astrocytes become reactive and respond by shortening and thickening their processes, similar to changes seen in reactive astrocytes of the glial lamina and myelinated optic nerve (Fig. 6G-I). However, the cell bodies of these astrocytes do not show significant hypertrophy. At $7 \mathrm{~d}$, some of these processes partially reextend (Fig. $6 \mathrm{~J}, K$ ). Thus, the overall pattern of retraction and thickening followed by reextension is similar for all the astrocytes within the CNS fiber tracts studied here.

\section{The phenotype of reactive astrocytes in the hGFAPpr-EGFP} mouse is representative of the native astrocyte population We performed two types of control experiments to verify that the changes observed in fibrous astrocytes were not artifacts of the transgenic strain. First, we examined reactive protoplasmic astrocytes within the cortex of hGFAPpr-EGFP mice after a stab lesion. The expected response of these astrocytes has been carefully described in C57BL/6 mice, where astrocytes were visualized by 
single-cell dye injections (Wilhelmsson et al., 2006). We found the same pattern of changes when the cells were visualized by EGFP expression. Normal protoplasmic astrocytes in the cortex of hGFAPprEGFP mice have a bushy morphology with many fine processes extending from the primary processes. Neighboring protoplasmic astrocytes maintain nonoverlapping spatial domains (Fig. 7A) (Bushong et al., 2002; Ogata and Kosaka, 2002; Wilhelmsson et al., 2006). At 3 d after crush, reactive protoplasmic astrocytes within hGFAPpr-EGFP mice appeared identical to those described by Wilhelmsson et al. (2006). There was hypertrophy of the primary processes (Fig. $7 B$, arrowheads) and an apparent increase in the number of primary processes leaving the soma and branchings (Fig. 7B). A striking feature in the response of protoplasmic astrocytes to injury is that they maintain their nonoverlapping spatial arrangement after becoming reactive. This was also observed for reactive protoplasmic astrocytes in the cortex of our hGFAPprEGFP mice (Fig. 7B), confirming the fidelity of EGFP expression as an astrocyte marker.

As a second control, we used an alternative method of visualizing the morphological changes of reactive astrocytes. Astrocytes in the normal and crushed optic nerves of age-matched C57BL/6 mice were labeled by particle-mediated transfer of DiI (see Materials and Methods). Dyelabeled astrocytes from the normal glial lamina appear similar to those in the hGFAPpr-EGFP mice. They have many long primary processes (Fig. $8 \mathrm{~A}$, arrowheads) ending with bulbous endfeet that contact the pial wall on the other side of the optic nerve (Fig. $8 \mathrm{~B}$, arrowheads). Reactive astrocytes in the $7 \mathrm{~d}$ after crush optic nerve showed hypertrophy and shortening of processes (Fig. $8 \mathrm{C}$, arrowheads), similar to changes in reactive astrocytes of the hGFAPprEGFP mice.

\section{Discussion}

The central question of this study was to resolve the structural changes undergone by fibrous astrocytes as they become "reactive." We used transgenic mice that express EGFP in subsets of astrocytes to study the structure of reactive fibrous astrocytes within the glial lamina, the myelinated portion of the optic nerve and the corpus callosum. Individual fibrous astrocytes undergo a two-stage remodeling process, first retracting and simplifying and then partially reextending their processes. In contrast, reactive protoplasmic astrocytes increase the number of processes and branches while maintaining their individual spatial domains throughout injury. This increases the density of processes filling that volume. The main common feature between the response of fibrous and protoplasmic astrocytes was the hypertrophy of the soma and remaining processes.

\section{Structural remodeling of fibrous astrocytes}

A simplification of the process architecture seems to be a common initial response of fibrous astrocytes to injury, as was also observed by Butt and Colquhoun (1996). Here we show that the morphological response of fibrous astrocytes occurs in two stages. In the first stage, many primary and higher-order processes retract, simplifying the overall shape of the astrocyte, and by $3 \mathrm{~d}$ after crush dramatically diminishing their spatial coverage by as much as eightfold. It is not known why astrocytes would react in such a way. The initial shortening of processes would be expected to cause a loss of gap-junctional coupling, a detachment of their endfeet from the pial wall and blood vessels, and of processes that might be associated with surviving axons. In addition, the reduction in their spatial domain, along with the loss of axons, means that the degenerating neuropil at some stage may contain a certain volume devoid of cellular elements.

In the second stage $(>7 \mathrm{~d})$, the processes partially reextend and thin again. Within the glial lamina, the processes that have reextended follow a tortuous path and do not organize themselves to form the honeycomb structure as seen in the normal glial lamina. This suggests that the presence of axons is required to guide the processes of astrocytes to form the glial tubes. The astrocytes do appear to regenerate at least a limited number of contacts with the pia and blood vessels, as well as an arbor of processes covering a substantial fraction of the degenerated nerve. Astrocytes therefore seem to contain a cell-intrinsic program that directs them to assume a more or less normal morphology and contact these target structures independent of the presence of axons. 


\section{How does the glial scar form?}

The appearance of the glial scar within the white matter (e.g., optic nerve and spinal cord) has been well documented by visualizing the GFAP labeling pattern, which reveals a dense and disorganized meshwork of thickened processes (Blaugrund et al., 1992; Frank and Wolburg, 1996; Podhajsky et al., 1997; SellésNavarro et al., 2001; Ohlsson et al., 2004; Okada et al., 2006; Howell et al., 2007; Herrmann et al., 2008). By visualizing EGFPexpressing reactive astrocytes, we show morphological changes that go unseen when reactivity is detected by GFAP labeling. For example, it was not possible to see that these astrocytes change shape and reduce the length of their processes so dramatically.

One question that emerges from the remodeling of these individual astrocytes is what fills in the space produced by the loss of axons. Also in the crushed optic nerve, Wohl et al. (2009) found a small increase in the number of astrocytes, but one unlikely to be sufficient to completely fill the space vacated by the loss of axons. In the brain, the source of newly divided scarforming astrocytes is not well established, and there are several potential possibilities. One line of evidence is that mature astrocytes can reenter the cell cycle and proliferate during scar formation (Bush et al., 1999; Buffo et al., 2008; Gadea et al., 2008). Evidence has also been presented that some proliferating reactive astrocytes can derive from NG2 progenitor cells in the local parenchyma (Magnus et al., 2008) or from ependymal cell progenitors after injury or stroke (Meletis et al., 2008; Carlén et al., 2009). Additionally, multipotent progenitors that express GFAP and reside in the subependymal tissue (Garcia et al., 2004) generate progeny cells that can migrate toward the site of injury after trauma or stroke (Ohab and Carmichael, 2008). In our experiments, hypertrophy of individual astrocytes does not appear to account for filling of the vacated space within the optic nerve. The thickness and the number of processes return to normal levels by 1 month after crush. Moreover, the spatial domain of individual astrocytes is, in fact, smaller after axonal degeneration than before (Fig. 4). We did not find significant cell proliferation within the glial lamina. Part of the loss of volume can be accounted for by the overall shrinkage of the degenerated nerve. Whether or not there is migration of cells from neighboring regions cannot be determined from our material.

\section{The functions of reactive astrocytes}

Reactive astrocytes and the glial scar have potentially both beneficial and detrimental effects. Scar-forming reactive astrocytes have been proposed to take up excitotoxic glutamate; provide protection from oxidative stress via glutathione production; repair the bloodbrain barrier; minimize neuronal loss, lesion size, and demyelination; limit the spread of an inflammatory response; and, in the long term, improve functional recovery (Rothstein et al., 1996; Bush et al., 1999; Faulkner et al., 2004; Swanson et al., 2004; Myer et al., 2006; Okada et al., 2006; Rolls et al., 2009; Sofroniew, 2009; Voskuhl et al., 2009).

There is also a growing understanding that dysfunction or effects of reactive astrocytes can contribute to or be primary sources of CNS damage, either through the loss of essential functions performed by astrocytes or reactive astrocytes, or through the gain of detrimental effects. Astrocytes play a critical role in the regulation of blood flow, homeostasis of ions, extracellular fluid and transmitters, energy provision, and synaptic function and remodeling (Ullian et al., 2001; Simard and Nedergaard, 2004; Christopherson et al., 2005; Pascual et al., 2005; Seifert et al., 2006; Iadecola and Nedergaard, 2007; Pellerin et al., 2007; Stevens et al., 2007; Rouach et al., 2008). Disruption in any of these normal processes has the potential to cause pathology. Astrocytes have the potential to gain detrimental effects. These can include release of excitotoxic glutamate; exacerbation of inflammation through cytokine production, a compromise of the blood-brain barrier through the production of vascular endothelial growth factor; production and release of reactive oxygen species; and release of inhibitory extracellular matrix components such as chondroitin sulfate proteoglycans (Swanson et al., 2004; Brambilla et al., 2005, 2009; Takano et al., 2005; Hamby et al., 2006; Yiu and He, 2006; Fitch and Silver, 2008; Argaw et al., 2009).

From a purely anatomical standpoint, the glial scar may provide beneficial structural support. For example, in a partial lesion, the scar functions as a scaffold to fill the space devoid of axons, preventing the tissue from collapsing or shrinking and thus causing deformation of the surviving axons. On the other hand, the classic detrimental effect of the glial scar is the inhibition of axon regeneration. It was traditionally thought that the scar provides a physical barrier for regeneration. In terms of the glial lamina, once a scar is formed within this region, it is difficult to see how, if axons were to regenerate, they would reorganize to form bundles with a topographic relationship to the retina (Fig. 9). In glaucoma, the glial lamina region (analogous to the lamina cribrosa region in humans) is thought to be the initial point of axonal degeneration (Quigley, 1999; Jakobs et al., 2005; Howell et al., 2007; Buckingham et al., 2008; Soto et al., 2008). Here, there is also extensive remodeling of the GFAP labeling pattern (Howell et al., 2007), and so the structural changes described in this study after nerve crush likely reflect the changes in glaucoma.

The morphological changes seen here seem to be a general feature of fibrous astrocytes in CNS fiber tracts. Why is a two-stage remodeling process necessary? The detachment of its processes from the surrounding structures is counterintuitive as such connections are normally required for astrocytes to perform their diverse functions. It would seem more efficient and quite possible for existing processes to simply form a new space-filling arrangement, or for astrocytes to extend more processes, rather than first simplifying and shortening their processes and later reextending them. Perhaps the changes in gene expression that occur during the different stages of remodeling would yield clues.

\section{References}

Anderson MG, Smith RS, Hawes NL, Zabaleta A, Chang B, Wiggs JL, John SWM (2002) Mutations in genes encoding melanosomal proteins cause pigmentary glaucoma in DBA/2J mice. Nat Genet 30:81-85.

Argaw AT, Gurfein BT, Zhang Y, Zameer A, John GR (2009) VEGFmediated disruption of endothelial CLN-5 promotes blood-brain barrier breakdown. Proc Natl Acad Sci U S A 106:1977-1982.

Blaugrund E, Duvdevani R, Lavie V, Solomon A, Schwartz M (1992) Disappearance of astrocytes and invasion of macrophages following crush injury of adult rodent optic nerves: implications for regeneration. Exp Neurol 118:105-115.

Brambilla R, Bracchi-Ricard V, Hu WH, Frydel B, Bramwell A, Karmally S, Green EJ, Bethea JR (2005) Inhibition of astroglial nuclear factor $\mathrm{kB}$ reduces inflammation and improves functional recovery after spinal cord injury. J Exp Med 202:145-156.

Brambilla R, Persaud T, Hu X, Karmally S, Shestopalov VI, Dvoriantchikova G, Ivanov D, Nathanson L, Barnum SR, Bethea JR (2009) Transgenic inhibition of astroglial NF-kB improves functional outcome in experimental autoimmune encephalomyelitis by suppressing chronic central nervous system inflammation. J Immunol 182:2628-2640.

Buckingham BP, Inman DM, Lambert W, Oglesby E, Calkins DJ, Steele MR, Vetter ML, Marsh-Armstrong N, Horner PJ (2008) Progressive gan- 
glion cell degeneration precedes neuronal loss in a mouse model of glaucoma. J Neurosci 28:2735-2744.

Buffo A, Rite I, Tripathi P, Lepier A, Colak D, Horn AP, Mori T, Götz M (2008) Origin and progeny of reactive gliosis: a source of multipotent cells in the injured brain. Proc Natl Acad Sci U S A 105:3581-3586.

Bush TG, Puvanachandra N, Horner CH, Polito A, Ostenfeld T, Svendsen CN, Mucke L, Johnson MH, Sofroniew MV (1999) Leukocyte infiltration, neuronal degeneration, and neurite outgrowth after ablation of scarforming, reactive astrocytes in adult transgenic mice. Neuron 23:297-308.

Bushong EA, Martone ME, Jones YZ, Ellisman MH (2002) Protoplasmic astrocytes in CA1 stratum radiatum occupy separate anatomical domains. J Neurosci 22:183-192.

Butt A, Colquhoun K, Berry M (1994a) Confocal imaging of glial cells in the intact rat optic nerve. Glia 10:315-322.

Butt A, Colquhoun K, Tutton M, Berry M (1994b) Three-dimensional morphology of astrocytes and oligodendrocytes in the intact mouse optic nerve. J Neurocytol 23:469-485.

Butt AM, Colquhoun K (1996) Glial cells in transected optic nerves of immature rats. I. An analysis of individual cells by intracellular dyeinjection. J Neurocytol 25:365-380.

Carlén M, Meletis K, Göritz C, Darsalia V, Evergren E, Tanigaki K, Amendola M, Barnabé-Heider F, Yeung MS, Naldini L, Honjo T, Kokaia Z, Shupliakov O, Cassidy RM, Lindvall O, Frisén J (2009) Forebrain ependymal cells are Notch-dependent and generate neuroblasts and astrocytes after stroke. Nat Neurosci 12:259-267.

Christopherson KS, Ullian EM, Stokes CC, Mullowney CE, Hell JW, Agah A, Lawler J, Mosher DF, Bornstein P, Barres BA (2005) Thrombospondins are astrocyte- secreted proteins that promote CNS synaptogenesis. Cell 120:421-433.

Connor JR, Berkowitz EM (1985) A demonstration of glial filament distribution in astrocytes isolated from rat cerebral cortex. Neuroscience 16:33-44.

Eddleston M, Mucke L (1993) Molecular profile of reactive astrocytes-implications for their role in neurologic disease. Neuroscience 54:15-36.

Emsley JG, Macklis JD (2006) Astroglial heterogeneity closely reflects the neuronal-defined anatomy of the adult murine CNS. Neuron Glia Biol 2:175-186.

Faulkner JR, Herrmann JE, Woo MJ, Tansey KE, Doan NB, Sofroniew MV (2004) Reactive astrocytes protect tissue and preserve function after spinal cord injury. J Neurosci 24:2143-2155.

Fitch MT, Silver J (2008) CNS injury, glial scars, and inflammation: Inhibitory extracellular matrices and regeneration failure. Exp Neurol 209:294-301.

Frank M, Wolburg H (1996) Cellular reactions at the lesion site after crushing of the rat optic nerve. Glia 16:227-240.

Gadea A, Schinelli S, Gallo V (2008) Endothelin-1 regulates astrocyte proliferation and reactive gliosis via a JNK/c-Jun signaling pathway. J Neurosci 28:2394-2408.

Gan WB, Grutzendler J, Wong WT, Wong RO, Lichtman JW (2000) Multicolor "DiOlistic" labeling of the nervous system using lipophilic dye combinations. Neuron 27:219-225.

Garcia AD, Doan NB, Imura T, Bush TG, Sofroniew MV (2004) GFAPexpressing progenitors are the principle source of constitutive neurogenesis in adult mouse forebrain. Nat Neurosci 7:1233-1241.

Halassa MM, Fellin T, Takano H, Dong J-H, Haydon PG (2007) Synaptic islands defined by the territory of a single astrocyte. J Neurosci 27:6473-6477.

Hamby ME, Hewett JA, Hewett SJ (2006) TGF-b1 potentiates astrocytic nitric oxide production by expanding the population of astrocytes that express NOS-2. Glia 54:566-577.

Herrmann JE, Imura T, Song B, Qi J, Ao Y, Nguyen TK, Korsak RA, Takeda K, Akira S, Sofroniew MV (2008) STAT3 is a critical regulator of astrogliosis and scar formation after spinal cord injury. J Neurosci 28:7231-7243.

Howell GR, Libby RT, Jakobs TC, Smith RS, Phalan FC, Barter JW, Barbay JM, Marchant JK, Mahesh N, Porciatti V, Whitmore AV, Masland RH, John SWM (2007) Axons of retinal ganglion cells are insulted in the optic nerve early in DBA/2J glaucoma. J Cell Biol 179:1523-1537.

Iadecola C, Nedergaard M (2007) Glial regulation of the cerebral microvasculature. Nat Neurosci 10:1369-1376.

Jakobs TC, Libby RT, Ben Y, John SW, Masland RH (2005) Retinal ganglion cell degeneration is topological but not cell type specific in DBA/2J mice. J Cell Biol 171:313-325.
Kettenmann H, Ransom BR (2005) Neuroglia. New York: Oxford UP.

Kong J-H, Fish DR, Rockhill RL, Masland RH (2005) Diversity of ganglion cells in the mouse retina: unsupervised morphological classification and its limits. J Comp Neurol 489:293-310.

Libby RT, Anderson MG, Pang IH, Robinson ZH, Savinova OV, Cosma IM, Snow A, Wilson LA, Smith RS, Clark AF, John SW (2005) Inherited glaucoma in DBA/2J mice: pertinent disease features for studying the neurodegeneration. Vis Neurosci 22:637-648.

Magnus T, Carmen J, Deleon J, Xue H, Pardo AC, Lepore AC, Mattson MP, Rao MS, Maragakis NJ (2008) Adult glial precursor proliferation in mutant SOD1G93A mice. Glia 56:200-208.

Meletis K, Barnabé-Heider F, Carlén M, Evergren E, Tomilin N, Shupliakov O, Frisén J (2008) Spinal cord injury reveals multilineage differentiation of ependymal cells. PLoS Biol 6:e182.

Myer DJ, Gurkoff GG, Lee SM, Hovda DA, Sofroniew MV (2006) Essential protective roles of reactive astrocytes in traumatic brain injury. Brain 129:2761-2772.

Nolte C, Matyash M, Pivneva T, Schipke CG, Ohlemeyer C, Hanisch UK, Kirchhoff F, Kettenmann H (2001) GFAP promoter-controlled EGFPexpressing transgenic mice: a tool to visualize astrocytes and astrogliosis in living brain tissue. Glia 33:72-86.

Oberheim NA, Tian G-F, Han X, Peng W, Takano T, Ransom B, Nedergaard M (2008) Loss of astrocytic domain organization in the epileptic brain. J Neurosci 28:3264-3276.

Oberheim NA, Takano T, Han X, He W, Lin JHC, Wang F, Xu Q, Wyatt JD, Pilcher W, Ojemann JG, Ransom BR, Goldman SA, Nedergaard M (2009) Uniquely hominid features of adult human astrocytes. J Neurosci 29:3276-3287.

Ogata K, Kosaka T (2002) Structural and quantitative analysis of astrocytes in the mouse hippocampus. Neuroscience 113:221-233.

Ohab JJ, Carmichael ST (2008) Poststroke neurogenesis: emerging principles of migration and localization of immature neurons. Neuroscientist 14:369-380.

Ohlsson M, Mattsson P, Svensson M (2004) A temporal study of axonal degeneration and glial scar formation following a standardized crush injury of the optic nerve in the adult rat. Restor Neurol Neurosci 22:1-10.

Okada S, Nakamura M, Katoh H, Miyao T, Shimazaki T, Ishii K, Yamane J, Yoshimura A, Iwamoto Y, Toyama Y, Okano H (2006) Conditional ablation of Stat 3 or Socs 3 discloses a dual role for reactive astrocytes after spinal cord injury. Nat Med 12:829-834.

Pascual O, Casper K, Kubera C, Zhang J, Revilla-Sanchez R, Sul J-Y, Takano H, Moss SJ, McCarthy K, Haydon PG (2005) Astrocytic purinergic signaling coordinates synaptic networks. Science 310:113-116.

Pellerin L, Bouzier-Sore AK, Aubert A, Serres S, Merle M, Costalat R, Magistretti PJ (2007) Activity-dependent regulation of energy metabolism by astrocytes: an update. Glia 55:1251-1262.

Podhajsky RJ, Bidanset DJ, Caterson B, Blight AR (1997) A quantitative immunohistochemical study of the cellular response to crush injury in optic nerve. Exp Neurol 143:153-161.

Quigley HA (1999) Neuronal death in glaucoma. Prog Retin Eye Res 18:39-57.

Ridet JL, Malhotra SK, Privat A, Gage FH (1997) Reactive astrocytes: cellular and molecular cues to biological function. Trends Neurosci 20:570-577.

Rolls A, Shechter R, Schwartz M (2009) The bright side of the glial scar in CNS repair. Nat Rev Neurosci 10:235-241.

Rothstein JD, Dykes-Hoberg M, Pardo CA, Bristol LA, Jin L, Kuncl RW, Kanai Y, Hediger MA, Wang Y, Schielke JP, Welty DF (1996) Knockout of glutamate transporters reveals a major role for astroglial transport in excitotoxicity and clearance of glutamate. Neuron 16:675-686.

Rouach N, Koulakoff A, Abudara V, Willecke K, Giaume C (2008) Astroglial metabolic networks sustain hippocampal synaptic transmission. Science 322:1551-1555.

Seifert G, Schilling K, Steinhäuser C (2006) Astrocyte dysfunction in neurological disorders: a molecular perspective. Nat Rev Neurosci 7:194-206.

Sellés-Navarro I, Ellezam B, Fajardo R, Latour M, McKerracher L (2001) Retinal ganglion cell and nonneuronal cell responses to a microcrush lesion of adult rat optic nerve. Exp Neurol 167:282-289.

Simard M, Nedergaard M (2004) The neurobiology of glia in the context of water and ion homeostasis. Neuroscience 129:877-896.

Sofroniew MV (2009) Molecular dissection of reactive astrogliosis and glial scar formation. Trends Neurosci 32:638-647. 
Sofroniew MV, Vinters HV (2010) Astrocytes: biology and pathology. Acta Neuropathol 119:7-35.

Soto I, Oglesby E, Buckingham B, Son J, Roberson E, Steele M, Inman D, Vetter M, Horner P, Marsh-Armstrong N (2008) Retinal ganglion cells downregulate gene expression and lose their axons within the optic nerve head in a mouse glaucoma model. J Neurosci 28:548-561.

Stevens B, Allen NJ, Vazquez LE, Howell GR, Christopherson KS, Nouri N, Micheva KD, Mehalow AK, Huberman AD, Stafford B, Sher A, Litke AM, Lambris JD, Smith SJ, John SW, Barres BA (2007) The classical complement cascade mediates CNS synapse elimination. Cell 131:1164-1178.

Sun D, Lye-Barthel M, Masland RH, Jakobs TC (2009) The morphology and spatial arrangement of astrocytes in the optic nerve head of the mouse. J Comp Neurol 516:1-19.

Swanson RA, Ying W, Kauppinen TM (2004) Astrocyte influences on ischemic neuronal death. Curr Mol Med 4:193-205.

Takano T, Kang J, Jaiswal JK, Simon SM, Lin JH, Yu Y, Li Y, Yang J, Dienel G, Zielke HR, Nedergaard M (2005) Receptor-mediated glutamate release from volume sensitive channels in astrocytes. Proc Natl Acad Sci U S A 102:16466-16471.

Ullian EM, Sapperstein SK, Christopherson KS, Barres BA (2001) Control of synapse number by glia. Science 291:657-661.

Voskuhl RR, Peterson RS, Song B, Ao Y, Morales LBJ, Tiwari-Woodruff S, Sofroniew MV (2009) Reactive astrocytes form scar-like perivascular barriers to leukocytes during adaptive immune inflammation of the CNS. J Neurosci 29:11511-11522.

Wilhelmsson U, Bushong EA, Price DL, Smarr BL, Phung V, Terada M, Ellisman MH, Pekny M (2006) Redefining the concept of reactive astrocytes as cells that remain within their unique domains upon reaction to injury. Proc Natl Acad Sci U S A 103:17513-17518.

Wohl SG, Schmeer CW, Kretz A, Witte OW, Isenmann S (2009) Optic nerve lesion increases cell proliferation and nestin expression in the adult mouse eye in vivo. Exp Neurol 219:175-186.

Yiu G, He Z (2006) Glial inhibition of CNS axon regeneration. Nat Rev Neurosci 7:617-627. 